\title{
Intervenção sociológica e a pesquisa com memória oral e história de instituições escolares
}

\author{
Sociological intervention and research with oral memory and history \\ of educational institutions
}

\author{
Reinaldo dos Santos \\ Professor Adjunto do Programa de Pós-Graduação em Educação da Universidade \\ Federal da Grande Dourados-UFGD. \\ reinaldosantos@ufgd.edu.br
}

Lincoln Christian Fernandes Professor colaborador pela Universidade Estadual de Mato Grosso do Sul-UEMS e professor de Ensino Médio pela Secretaria de Estado da Educação/MS; Mestre em História da Educação pelo PPGEdu-UFGD. proflincolnbarizon@yahoo.com.br

\begin{abstract}
Resumo
O artigo trata das novas abordagens no campo da história da educação e da temática da história e memória de instituições escolares. O objeto em estudo sob essa nova abordagem é a memória (ou esquecimento) do cotidiano escolar de instituições de ensino públicas de regiões interioranas. A problemática refere-se à falta de políticas públicas de arquivamento dos documentos de memória do cotidiano escolar. O objetivo principal deste texto é demonstrar a importância da intervenção sociológica na condição de referencial de análise na pesquisa histórica. Como hipótese, especialmente por inserir a comunidade na realização da pesquisa, a própria metodologia acaba possibilitando a identificação do laço social e a construção da identidade da comunidade escolar. Por último, a intervenção oportuniza a organização de um arquivo de memória oral do cotidiano escolar, em formato digitalizado.
\end{abstract}

Palavras-chave: História de instituições escolares. História oral. Intervenção sociológica. Memória social.

\begin{abstract}
The article deals with new approaches in the history field of the education and in the theme of history and memory of school institutions. The study objects under this new approach concerns the memory (or its forgetting) of the daily school life of public education institutions of teaching and country regions. The problematic tells the lack of public policies for archiving of documents in memory of school daily life. The main objective of this text is to demonstrate the importance of sociological intervention of referential condition of analysis in historical research. As a hypothesis, especially by inserting the community in the implementation of the research, the methodology itself ends up allowing the identification of the social link and the construction of the identity of the school community. Finally, the intervention favors the organization of an archive of oral memory of daily school in digitized format.
\end{abstract}

Key words: Sociological intervention. History of educational institutions. Oral history social memory. 


\section{Introdução}

O trabalho propõe a análise do referencial metodológico utilizado na investigação realizada no Programa de Mestrado em Educação (PPGEdu) da Universidade Federal da Grande Dourados, na linha de pesquisa: História da Educação, Memória e Sociedade. Discutem-se as novas abordagens e fontes orais no campo de investigação da História da Educação, sob o entendimento de que a pesquisa neste campo e a temática que aborda vêm ganhando espaço cada vez maior entre pesquisadores das Ciências Humanas e Sociais. Por isso, torna-se fundamental a compreensão de novas metodologias capazes de auxiliar os pesquisadores que se propõem a investigar novos objetos, novas fontes e novas temáticas.

Dessa forma, o artigo traz como proposta principal a verificação do potencial e relevância da metodologia da Intervenção Sociológica, de Touraine (1982), no campo da História da Educação. É preciso destacar que a questão das fontes apareceu como uma das problemáticas no contexto do objeto definido para investigação deste trabalho, pois as fontes escritas sempre foram tratadas como documentos oficiais, mas isso para a história tradicional. No entanto, a partir da "Nova História" defendida por Le Goff (1992) e Burke (1992) e, principalmente, com a "História Cultural" de Chartier (1993), as novas fontes passaram a ter validade reconhecida cientificamente, em especial a oralidade. Sobre o uso e especialmente quando o pesquisador tem à frente um novo objeto, surge também a necessidade de problematização diferenciada.

Ao tomar a memória das instituições escolares da rede pública da educação básica, classificadas como não confessionais, de regiões interioranas ou não centrais como objeto de pesquisa, logo se pode apontar que há uma quantidade mínima de documentos escritos por falta de arquivamento. Esse apontamento decorre da observação de campo realizado na cidade de Dourados/MS, em visita às instituições com maior tempo de estabelecimento no perímetro urbano. Além disso, alguns pesquisadores também já apontaram a realidade dos arquivos públicos de memória no interior, a exemplo de Amado (1990, p. 11), na obra "República em migalhas", em que afirma:

Se o problema do mau estado de conservação e de desorganização dos documentos históricos é sentido em todo o país, 
ainda mais agudo ele se apresenta na maioria das instituições estaduais e municipais, principalmente as situadas nas regiões mais pobres.

De acordo com as críticas dessa autora sobre as dificuldades de arquivamento e conservação da documentação de valor regional e local, as áreas marginalizadas sofrem com a falta de centros de memória, dificultando sobremaneira a pesquisa sobre a história dessas regiões. O interior, de modo geral, apresenta limitações mais acentuadas, o que amplia as evidências de ausência de políticas públicas de incentivo à constituição de acervo com fins de preservação da memória social.

Diante da constatação da quase inexistência de documentos de memória coletiva produzidos no cotidiano escolar, a proposta de investigação se realizou por meio de um Plano de Intervenção que buscou o envolvimento de professores(as), alunos(as) e comunidade na produção de documento oral e na organização de um centro de documentação escolar como núcleo preservacionista. Portanto, o caminho percorrido na pesquisa pôs foco na criação de um acervo de memória oral especialmente dedicado a apreender as lembranças de membros da comunidade escolar da instituição tomada para estudo. A utilização desse referencial metodológico foi fundamental para alcançar o objetivo principal da pesquisa: a sistematização de novas tecnologias da informação para fomentar a criação de centros de documentação informatizados no interior das próprias instituições escolares. A intenção deste texto é abordar apenas os novos referenciais de abordagem de pesquisas no campo da História da Educação, deixando claro que a Intervenção Sociológica já é bastante conhecida entre pesquisadores das Ciências Sociais, mas especialmente nova entre historiadores da educação.

A opção pelo referencial metodológico tem um grande significado para o pesquisador, podendo ser entendido como eixo norteador da investigação, uma espécie de bússola a orientar o trabalho de historiadores. Sobre o uso da Intervenção Sociológica como metodologia, é importante destacar sua presença no campo da pesquisa social. Assim, ao se apropriar desse referencial para a pesquisa histórica, torna-se necessário reconhecer a Historia Cultural como referencial teórico, dada a possibilidade de desenvolvimento de pesquisas na perspectiva da interdisciplinaridade entre Ciências Humanas e Sociais. 
Compreende-se que, abordando na pesquisa a relação entre as instituições educacionais públicas e a memória social pelo processo de intervenção na realidade escolar com o método da pesquisa-ação, ou seja, pelo envolvimento de professores(as), alunos(as) e comunidade na produção do conhecimento, o resultado no médio e longo prazos é permitir a criação de laços sociais. Esse procedimento metodológico torna evidente a riqueza de tal tipo de intervenção para os membros que fizeram parte da história (passado), para os que atuam no presente e para os que, no futuro, farão parte da instituição escolar.

Como proposta de intervenção na realidade escolar, a pesquisa-ação é considerada, segundo Thiollent (1988), uma investigação social que associa os dados coletados na realidade experimentada (universo empírico) a uma ação e a uma resolução de um problema coletivo no qual os atores da pesquisa se envolvem de forma cooperativa e colaborativa. Esse contexto oportunizou a escrita deste artigo sobre a fase principal do desenvolvimento da pesquisa com a Intervenção Sociológica, abrangendo, primeiro, a criação de um manual de elaboração de projeto de intervenção específico em memória da educação escolar, e, posteriormente, a própria elaboração do projeto de intervenção da escola escolhida.

\section{Os primeiros passos no caminho da intervenção}

Um dos primeiros e mais importantes passos na execução de intervenção na realidade de uma instituição escolar é, com certeza, a elaboração do Plano de Intervenção. Constitui uma das tarefas decisivas na trajetória de pesquisadores que buscam desenvolver novos estudos no campo da História da Educação. Porém, torna-se necessário pensar novos objetos e novas temáticas para que o uso da metodologia da Intervenção Sociológica faça sentido. Outro aspecto importante a ser considerado diz respeito aos documentos e fontes da pesquisa com intervenção numa situação de "esquecimento" da memória, pois pode acontecer que, no desenvolvimento do trabalho investigativo, o pesquisador avalie que as chamadas fontes tradicionais representam uma limitação à coleta de dados. Isso ocorre principalmente pela baixa expressão dos documentos arquivados nas instituições escolares em relação ao cotidiano.

Nesse contexto, optar pelo uso do documento oral requer discernimento quanto a sua especificidade no tratamento com o próprio tema da pesquisa. A utili- 
zação do documento oral constitui fonte imprescindível na busca por elementos da vida cotidiana, contribuindo para o protagonismo de culturas singulares, com destaque para a cultura escolar. Garrido (1995, p. 36) a compreende como "[. . . ] uma fonte documental a mais [...]" no referencial da pesquisa, mas que corresponde a um "[. . .] indispensável elemento de trabalho [. . .]".

Verifica-se que a exploração da oralidade na pesquisa sobre memória do cotidiano escolar não se limita ao uso mecânico da técnica de entrevista; ao contrário, o momento da entrevista requer, necessariamente, sensibilidade e uma estratégia bem elaborada no Plano de Intervenção para conseguir a maior adesão possível dos membros convidados da comunidade e clareza quanto ao objetivo principal da pesquisa, qual seja, a criação do centro de documentação escolar informatizado.

Partindo da elaboração minuciosa de um Plano de Intervenção que objetiva apreender a memória oral para criação de um centro de documentação, pode-se dizer que a Intervenção Sociológica configura uma metodologia imprescindível para trazer à tona a história local. A utilização do documento oral no levantamento de vestígios da história, especialmente para grupos até então marginalizados ou relegados ao esquecimento por versões oficiais do conhecimento, é fundamentada por Garrido (id.ib.) nos seguintes termos:

[...] é importante precisar que o uso das fontes orais permite não apenas incorporar indivíduos ou coletividades até agora marginalizados ou pouco representados nos documentos arquivísticos mas também facilita o estudo de atos e situações que a racionalidade de um momento histórico concreto impede que apareçam nos documentos escritos. Assim, portanto, as fontes orais possibilitam incorporar não apenas indivíduos à construção do discurso do historiador, mas nos permite conhecer e compreender situações insuficientemente estudadas até agora.

Percebe-se que o Plano de Intervenção deve prioritariamente apontar para o trabalho dedicado à memória oral. A indicação do documento oral para realização da ação se justifica, especialmente, pela possibilidade de incluir indivíduos e grupos esquecidos e por proporcionar o contato com atos e situações que dificilmente apareceriam em documentos escritos. 


\section{Intervenção e produção de depoimentos contra o esquecimento da memória escolar}

Neste trabalho também se pretende estabelecer uma reflexão sobre fontes de pesquisa em História da Educação, principalmente para a história de instituições escolares na perspectiva da intervenção na realidade. Trata-se de uma análise sobre uma opção de investigação científica que propõe o envolvimento dos sujeitos escolares no processo de pesquisa para apreender a memória do cotidiano escolar, investigação que se realiza no interior da própria instituição de ensino produzindo fontes orais e constituindo um núcleo de preservação da memória escolar.

A discussão sobre as fontes históricas é sempre relevante e um tema permanente da historiografia. O objetivo, aqui, é recorrer à memória dos atores educacionais não apenas como fonte histórica, mas também como objeto da pesquisa histórica. De acordo com Ragazzini (2001, p. 14):

[... ] a fonte é o único contato possível com o passado que permite formas de verificação. Está inscrita em uma operação teórica produzida no presente, relacionada a projetos interpretativos que visam confirmar, contestar ou aprofundar o conhecimento histórico acumulado.

É assim que essa proposta vai ao encontro da abordagem pela Intervenção Sociológica e utiliza a história oral como metodologia para envolver os sujeitos da escola na produção dos depoimentos orais dos diferentes segmentos que constituem as comunidades escolares. Nessa perspectiva, a metodologia se torna uma ferramenta importante para o historiador da educação. Sobre o uso da história oral, a autora da obra "Manual de História Oral", Verena Alberti (2005, p. 29), diz:

Sendo um método de pesquisa, a história oral não é um fim em si mesma, e sim um meio de conhecimento. Seu emprego só se justifica no contexto de uma investigação científica, o que pressupõe sua articulação com um projeto de pesquisa previamente definido. 
Compreende-se que, abordando a relação entre a história das instituições escolares e a memória pelo processo de intervenção na realidade escolar, buscando coletar narrativas orais, o esquecimento dá lugar à memória. Torna-se significativa a riqueza de informações para profissionais da educação, estudantes, pais e comunidade escolar em geral pelo fato de o processo de pesquisa propiciar a discussão em torno da história local e inserir situações cotidianas do ambiente escolar na história do lugar.

Quando se propõe a produção de documentos orais e a criação do centro de documentação para preservar a memória do cotidiano escolar, é preciso ressaltar a importância de outros documentos que podem surgir no decorrer da pesquisa, principalmente os de posse particular. Há que se considerar que a iniciativa de criar o acervo digital parte do pressuposto de que o depoimento deve ser compreendido como principal documento, mas não como único. A metodologia da história oral apresenta diferentes caminhos no uso das fontes orais em trabalhos de investigação científica: híbrida, pura, complementar e principal.

A diferença mais visível fica entre a "híbrida" e a "pura". Meihy (1996) entende que a primeira representa um trabalho de conjugação da coleta de depoimentos com outras fontes; a segunda busca apenas os testemunhos e obedece à valorização única do que foi dito. Já entre a "complementar" e a "principal", a distinção básica está em que na primeira a fonte oral complementa as fontes escritas, a estas conferindo um peso mais significativo, e na outra, a fonte oral aparece como o principal recurso, mas também conta com as fontes tradicionais.

Com base nessas observações, reforçamos ser fundamental que os sujeitos escolares se debrucem sobre o estudo do método antes de sair fazendo entrevistas. Vidal (1998), ao relatar sua experiência na pesquisa de doutoramento com a utilização da história oral, reafirmou a importância do uso de documentos diversos. Um dos primeiros e mais importantes passos na elaboração do Plano de Intervenção é a escolha dos tipos de documentos que devem ser utilizados na apreensão da memória coletiva, tarefa decisiva na trajetória da pesquisa-ação, já que esta metodologia busca relacionar o processo investigativo a uma diretiva de aprendizagem e de produção de conhecimento coletivas e à intervenção na realidade. Tratando-se, por exemplo, de uma intervenção com o envolvimento da classe estudantil na produção dos depoimentos, a pesquisa-ação fortalece propostas de formação de sujeitos escolares. 
A obra de Verena Alberti (2005) permite analisar os passos necessários para a realização de entrevistas no contexto da intervenção no interior da instituição. A pesquisadora trata da elaboração de roteiros, desde as preparações da véspera da entrevista, perpassando pela relação entre entrevistado e entrevistador, circunstâncias, duração e o papel do gravador na condução da entrevista, bem como os esclarecimentos necessários ao entrevistado quanto à cessão de direitos sobre o depoimento a ser realizado, cessão esta que deve estar acompanhada da transcrição total da entrevista, para que os resultados da coleta possam ser avaliados pelo próprio entrevistado, que de todo modo está compromissado com a mudança de determinada situação em que está inserido. Ainda conforme essa mesma autora, a história oral na perspectiva da pesquisa com história e memória das instituições escolares atua como

[...] um método de pesquisa (histórica, antropológica, sociológica,...) que privilegia a realização de entrevistas com pessoas que participaram de, ou testemunharam acontecimentos, conjunturas, visões de mundo, como forma de se aproximar do objeto de estudo. (ALBERTI, 1989, p. 52).

Thompson (1992) afirma que a história oral abre possibilidades e vozes aos esquecidos; Garrido (1995) defende a revitalização possível pela fonte oral para a história que era contada apenas pelas vias oficiais. Entretanto, para esta autora, a oralidade na pesquisa apresenta seus próprios caminhos, quando diz que "A memória é essencialmente seletiva e, por isso mesmo, parcial e interessada [...]", e que "[...] uma entrevista concreta não é mais que uma parte do conjunto e somente adquire seu real significado no todo que integra a amostra [...]" (GARRIDO, 1995, p. 38). Assim, a intervenção representa a possibilidade de jogar contra a manipulação da memória. Conforme Le Goff (1992, p. 426), "[...] tornarem-se senhores da memória e do esquecimento é uma das grandes preocupações das classes, dos grupos, dos indivíduos que dominaram e dominam as sociedades históricas".

Outros autores pedem atenção especial ao trabalho de utilização da história oral enquanto uma metodologia de pesquisa relacionada principalmente à história local, alertando para a proximidade do historiador e a necessidade de não perder de vista o objetivo determinado no projeto acerca do objeto em investigação: 
A História Local requer um tipo de conhecimento diferente daquele focalizado no alto nível de desenvolvimento nacional e dá ao pesquisador uma idéia muito mais imediata do passado. Ele a encontra dobrando a esquina e descendo a rua. Ele pode ouvir seus ecos no mercado, ler o seu grafite nas paredes, seguir suas pegadas nos campo [...] Os materiais básicos do processo histórico devem ser constituídos de quaisquer materiais que estejam à disposição no local. (SAMUEL, 1990, p. 220).

Outra voz acadêmica enfatiza a bidirecionalidade do processo de interação que se dá na história oral, na medida em que ela proporciona informações não somente significativas como únicas sobre o passado, podendo também transmitir a consciência individual ou coletiva, transformando-se ou não em instrumento de mudança:

\begin{abstract}
A história oral nãoé necessariamente um instrumento de mudança; isso depende do espírito com que seja utilizada. Não obstante, a história oral pode certamente ser um meio de transformar tanto o conteúdo quanto a finalidade da história. Pode ser utilizada para alterar o enfoque da própria história e revelar novos campos de investigação; pode derrubar barreiras que existam entre professores e alunos, entre gerações, entre instituições educacionais e o mundo exterior; e na produção da história - seja em livros, museus, rádio ou cinema - pode devolver às pessoas que fizeram e vivenciaram a história um lugar fundamental, mediante suas próprias palavras. (THOMPSON, 1992, p. 136).
\end{abstract}

Os desafios desse tipo de trabalho dizem respeito a sua busca por uma intervenção na realidade de instituições escolares de pouca tradição em preservação da memória, principalmente por se configurar como uma pesquisa no campo da História da Educação. Lembrando que trabalhos científicos de intervenção são raros neste campo e muito mais comuns nas Ciências Sociais e Políticas, ao se propor uma intervenção na realidade social de uma escola escolhida para estudo de caso, torna-se necessário o diálogo com referências da pesquisa social. May (2004) avalia que, além da oportunidade de também trabalhar com o método 
da pesquisa-ação e da necessidade de conjugação de referenciais de abordagem, é preciso trabalhar com o hibridismo metodológico. Parte-se da compreensão de que tanto a História Oral quanto a Intervenção Sociológica oferecem suporte metodológico para refletir sobre os rumos da intervenção. Então, além de trabalhar a abordagem pela metodologia da Intervenção Sociológica, também se pode estabelecer estratégias definidas pela metodologia da História Oral. Ressalte-se que essa abordagem de intervenção é pouco utilizada na pesquisa entre historiadores da educação, cabendo aqui lembrar o sociólogo considerado o grande expoente da metodologia de intervenção, Alain Touraine, que, conforme Palhares (2004, p. 163), entende que "O método de intervenção sociológica tem como uma de suas metas o conhecimento [...]". Touraine (1982, p. 45) defende, agora em seus próprios termos, que a abordagem pela intervenção " [. . . ] procura também elevar o nível de ação, proporcionar à ação real uma aproximação cada vez maior ao máximo de ação possível. Procura ajudar os homens a fazer a sua história [. . .]".

Portanto, nas pesquisas sobre a temática da história e da memória de instituições escolares que atuam com a abordagem de intervenção, é possível apontar sua validade para a produção de conhecimento em programas de pósgraduação stricto sensu direcionados à pesquisa-ação na realidade social das escolas de regiões interioranas e não centrais. Dessa forma, a pesquisa no campo da história da educação também pode trabalhar na perspectiva de deixar uma contribuição para reverter situações de fragilidades de grupos ou classes sociais, ligadas ou não às instituições de ensino, que sofrem com o esquecimento da memória coletiva e enfrentam uma perda de (re)conhecimento dos saberes que construíram na prática.

\section{Considerações finais}

O grande desafio desta pesquisa diz respeito a sua proposta de intervenção na realidade de uma instituição escolar para criação de um núcleo preservacionista da memória do cotidiano escolar, especialmente por se configurar como uma pesquisa de caráter interdisciplinar.

Contudo, ao trazer a proposta de trabalhar na perspectiva de promover uma intervenção em instituição de ensino, também se faz necessário enfatizar a importância de garantir a sistematização da tecnologia da informação, pensando 
na hipótese de fomentar a criação de um centro de documentação escolar que garanta a preservação da memória social em instituições escolares públicas do interior e de regiões não centrais.

Outra hipótese verificada ao fim da intervenção refere-se à expectativa de a ação ganhar significado no processo de ensino-aprendizagem, com grande potencial para atingir os indivíduos participantes da intervenção e os colaboradores da comunidade, por meio de ação e conscientização, como sujeitos da história.

Assim, com os resultados obtidos na instituição escolar por meio da intervenção, surgiu a hipótese do trabalho final: no uso de um itinerário de execução, a intervenção pode servir de referência para professores, alunos e comunidade buscarem apreender a memória e, em torno disso, estimular a criação de laços sociais que permitam a construção da identidade em diferentes comunidades escolares.

\section{Referências}

ALBERTI, Verena. Manual de história oral. 3. ed. Rio de Janeiro: Editora FGV, 2005. . História oral: a experiência do CPDOC. Rio de Janeiro: Centro de Pesquisa e Documentação de História Contemporânea do Brasil, 1989.

AMADO, Janaína. História e região: reconhecendo e construindo espaços. In: SILVA, Marcos A. da. República em migalhas: história regional e local. São Paulo: Marco Zero, 1990. BURKE, Peter. A escrita da história: novas perspectivas. São Paulo: Editora Unesp, 1992. CHARTIER, Roger. A bistória cultural: entre práticas e representações. Lisboa: Bertrand Brasil, 1993.

GARRIDO, Joan del Alcàzar. As fontes orais na pesquisa histórica: uma contribuição ao debate. Tradução de Alberto Aggio. In: Revista Brasileira de História, São Paulo, v. 13, n. 25, set. 92/ago., 1993, p. 33-54.

LE GOFF, J. História e memória. Tradução Bernardo Leitão. 2. ed. Campinas, São Paulo: Editora Unicamp, 1992.

MAY, Tim. Perspectiva da pesquisa social científica. In: MAY, Tim. Pesquisa social: questões, métodos e processos. Porto Alegre: Artmed, 2004.

MEIHY, José Carlos Sebe Bom. Manual de história oral. São Paulo: Loyola, 1996.

OLIVEIRA, Rosiska D.; OLIVEIRA, Miguel D. Pesquisa social e ação educativa. In: BRANDÃO, Carlos Rodrigues (Org.). Pesquisa participante. São Paulo: Brasiliense, 1981.

PALHARES, Marina Silveira. O método da intervenção sociológica. Revista da Educação Pública, Cuiabá, v. 8, n. 14, jan./jun., 2000. 
POLLACK, Michael. Memória, esquecimento, silêncio. Estudos Históricos, Rio de Janeiro, v. 2, n. 3, 1989, p. 3-15.

PORTELLI, Alessandro. Ensaios de história oral. São Paulo: Letra e Voz, 2010.

RAGAZZINI, Dario. Para quem e o que testemunham as fontes da história da educação? Educar, Curitiba, n. 18, 2001, p. 13-28.

SAMUEL, Raphael. História local e história oral. Revista Brasileira de História, São Paulo, v. 9, n. 19, p. 219-243, set. 89/fev., 1990.

SANTOS, Reinaldo; SARAT, Magda. História oral como fonte: apontamentos metodológicos e técnicas da pesquisa. In: COSTA, Célio Juvenal; MELO, José Joaquim Pereira; FABIANO, Luiz Hermenegildo (Org.). Fontes e métodos em história da educação. Dourados, MS: Ed.UFGD, 2010, p. 49-78.

THIOLLENT, Michel. Metodologia da pesquisa-acão. São Paulo: Cortez; Autores Associados, 1988.

THOMPSON, Paul. A voz do passado: história oral. 3. ed. Rio de Janeiro: Paz e Terra, 1992.

TOURAINE, Alain. O método da sociologia da ação: a intervenção sociológica. Tradução Danielle Ardaillon. Novos Estudos, Cebrap. ano 1, n. 3, p. 36-45. jul. 1982. (originalmente publicado na Revue de Sociologie Schweiz - Ges. F. Soziologie/Soc. Suisse de Sociologie).

VIDAL, Diana G. A fonte oral e a pesquisa em história da educação: algumas considerações. Educação em Revista, Belo Horizonte, n. 27, jul., 1998, p. 7-16.

recebido em 5 abr. 2011 / aprovado em 31 jul. 2012

Para referenciar este texto:

FERNANDES, L. C.; SANTOS, R. Intervenção sociológica e a pesquisa com memória oral e história de instituições escolares. Dialogia, São Paulo, n. 15, p. 49-60, 2012. 